\title{
Point: Healthcare Providers Should Receive Treatment Priority During a Pandemic
}

\author{
Kirk R Daffner, MD
}

Harvard Medical School, Boston, Massachusetts; The Center for Brain/Mind Medicine, Department of Neurology, Brigham and Women's Hospital, Boston, Massachusetts.

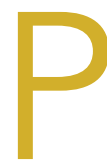

otential catastrophic surges in coronavirus disease 2019 (COVID-19) are leading to more patients requiring intensive care unit beds than are available, prompting hospitals to prepare to activate crisis standards of care (CSC). ${ }^{1,2}$ These guidelines manage the sobering process of determining which gravely ill patients will have access to limited ventilators, critical care specialists, and other essential hospital personnel. As a member of the CSC triage team at Brigham and Women's Hospital, Boston, Massachusetts, during the initial surge, ${ }^{1}$ I was taught how to follow procedures that assign each patient a priority score that ranged from 1 to 8, with lower scores representing higher priority. Scoring decisions were largely based on current status of organ systems and major medical illnesses (predictive of short-term and longer-term survival, respectively), consistent with the objective of maximizing lives and life-years saved. ${ }^{1,3-7}$ Other parameters included improving the priority score of a pregnant woman with a viable fetus and breaking ties in favor of younger patients who had not lived through life's major stages. ${ }^{4,7}$ One issue that elicited sharp disagreement among my colleagues was whether healthcare providers (HCPs; eg, physicians, nurses) should be treated any differently than other individuals.

I believe that HCPs should receive treatment priority during a pandemic because the community has a special obligation to those workers willing to risk serious illness by providing care to potentially infected patients.

\section{THE UTILITARIAN CASE FOR TREATMENT PRIORITIZATION}

The most common argument for prioritizing HCPs has been made on utilitarian grounds: save individuals who can save others. ${ }^{3,4,6}$ Such an approach is not founded on the claim that HCPs have higher intrinsic worth, but is based on the instrumental value of HCPs to keep others alive. ${ }^{4,6}$ An abiding concern for human life demands systems to ensure individuals with clinical expertise are protected so that they can use their skills to maximize the number of lives saved. A similar case has been made to justify prioritizing HCPs for early access to vaccines during a pandemic. ${ }^{5}$ To underscore these issues, imagine a scenario in

Corresponding Author: Kirk R Daffner, MD; Email: kdaffner@bwh.harvard.edu; Telephone: 617-732-8060; Twitter: @krdaffner.

Published online first February 17, 2021

Received: October 29, 2020; Revised: January 7, 2021;

Accepted: January 21, 2021

๑ 2021 Society of Hospital Medicine DOI 10.12788/jhm.3596 which, because of serious illness among HCPs, there were not enough workers with requisite expertise to care for the rest of the community in which a virus was rapidly spreading. Prioritizing HCPs could mitigate this sequence of events by preventing them from becoming infected through early access to vaccinations or promoting their recovery from the illness, which might allow them to return to work caring for others.

\section{THE ROLE OF SPECIAL OBLIGATIONS}

Although the utilitarian argument has merit, my primary reason for advocating the prioritization of HCPs reflects a different ethical framework that emphasizes the reciprocal obligations between HCPs and the community. Obligations of physicians have been framed in terms of the commitments made to their self-chosen profession and the putative social contract that has been constructed with the community. ${ }^{8-10}$ These principles are well articulated in the American Medical Association's (AMA's) Code of Medical Ethics, which states, "Because of their commitment to care for the sick and injured, individual physicians have an obligation to provide urgent medical care during disasters... even in the face of greater than usual risks to their own safety, health, or life." ${ }^{10,11}$ Although the AMA qualified its position by indicating that this obligation is not unconditional, it still formulated exceptions within the overarching structure of professional duty, allowing physicians to "balance immediate benefits to individual patients with ability to care for patients in the future." ${ }^{11,12}$

If one accepts that HCPs have a professional obligation to take care of sick members of the community, even in perilous situations, what, if any, reciprocal obligation does the community have to its HCPs? Reciprocity is a fundamental ethical principle, ${ }^{13}$ serving as a foundation for the Golden Rule, which is a component of almost every ethical tradition. ${ }^{14}$ At its core, reciprocity asks us to treat other people as we would want to be treated. It requires endeavoring to take the perspective of others. Within this framework, a strategy for generating a just policy about treatment prioritization is to develop it under the assumption of not knowing which role one would end up playing in a situation. It is critical that if the positions of the individuals involved were reversed, the same rules and obligations would be accepted as fair. ${ }^{13}$ I suggest that if members of the community put themselves in the shoes of HCPs who are willing to risk exposure to a potentially deadly virus, they would acknowledge the legitimate expectation of HCPs to receive prioritized care if they became ill from the infection.

In most cases, reciprocity is not construed as requiring an identical exchange, but a fair one in which, for instance, sacrifice is returned in kind. Obligations can be viewed as debts that 
we either owe or are entitled to receive. ${ }^{15}$ In the current context, reciprocal obligations are derived from the relationship between HCPs and the community in which they serve. HCPs have a special set of obligations to carry out their work with a high degree of professionalism. If circumstances demand they take on substantial risk for their community, the community, in turn, has a special obligation to take care of them.

To highlight this perspective, imagine HCPs who become ill with COVID-19 and make claims for treatment priority despite having been unwilling to work with patients who are sick with COVID-19. We would consider such claims to be unjust because our moral intuition suggests that individuals are owed a debt for the actual risks they have taken, not for the potential ones they have avoided. A corollary of this view is that HCPs who have demonstrated a willingness to risk their lives contracting COVID-19 have a legitimate claim for prioritization.

\section{IMPLEMENTATION}

Acknowledgment of the community's special obligation to HCPs does not negate competing claims for prioritization, such as trying to save the most lives or accounting for a patient's pregnancy status and stage of life. Rather, there is a need for CSC guidelines to also include recognition of the special obligations owed HCPs by improving their priority score in the calculus used to triage care. Operationalizing the process would need to be worked out. One possibility would be for HCPs directly caring for patients ill from COVID-19 to have their priority score improve by 2 points, and HCPs directly caring for patients without known disease (but who could still be infectious) to benefit by 1 point. At a minimum, recognition of the risks taken should serve as a tiebreaker in favor of these workers.

\section{TO WHOM DOES THE COMMUNITY HAVE A SPECIAL OBLIGATION?}

If we acknowledge that during a pandemic, the community has a special obligation to HCPs because of the risks they are taking to serve others, by the same logic, this commitment should be extended to any personnel linked to the healthcare system (eg, employees in environmental services) or frontline workers providing essential services (eg, grocery store workers) who are taking similar risks that involve exposure to potentially infected individuals. Conversely, HCPs who are working exclusively from home via telemedicine should not receive treatment priority. An approach that extends treatment prioritization to other relevant workers mitigates concerns raised about prioritizing scarce critical care resources to an already advantaged class of individuals (ie, HCPs) as well as the negative optics of a committee of "deciders" in a hospital who are privileging care to their own members. ${ }^{12}$

\section{CONCLUSION}

Reciprocity, a critical component of our notion of justice, should be incorporated into CSC guidelines. The community's reciprocity to HCPs and frontline workers needs to be commensurate with the sacrifice made by these groups. Although public demonstrations of gratitude may be much appreciated, such displays alone are not adequate for honoring the community's special obliga- tions. If, during a pandemic, HCPs or frontline workers deliver direct care or services to members of the community, despite serious risk to their own lives, the community has a reciprocal obligation to these individuals to prioritize their access to critical care. HCPs and frontline workers should be prioritized not because their lives have higher intrinsic worth or solely as a reflection of their instrumental value to the community, but out of recognition of the special debt owed them. This is not an unconditional obligation, but one that should be built into the complex, multifaceted decision-making process ${ }^{4,6,16}$ underlying the allocation of scarce medical resources in a pandemic.

\section{Acknowledgments}

The author deeply appreciates the thoughtful comments on the essay from William Snyder, PhD, Melissa Frumin, MD, Brittany McFeeley, BS, Lise Bliss, MBA, and especially Seth Gales, MD, and remains grateful for the guidance and support he received early in his academic career from his first mentors, Carol Gilligan, PhD, and Michael Walzer, PhD.

Disclosures: The author has nothing to disclose.

\section{References}

1. Milliken A, Jurchak M, Sadovnikoff N, et al. Addressing challenges associated with operationalizing a crisis standards of care protocol for the Covid-19 pandemic. NEJM Catalyst. 2020:1-14. https://doi.org/10.1056/CAT.20.0384

2. Paquette ET, Derrington S, Fry JT, et al. Shifting duties of children's hospitals during the COVID-19 pandemic. J Hosp Med. 2020;15(10):631-633. https:// doi.org/10.12788/jhm.3490

3. Emanuel EJ, Persad G, Upshur R, et al. Fair allocation of scarce medical resources in the time of Covid-19. N Engl J Med. 2020;382(21):2049-2055. https://doi.org/10.1056/NEJMsb2005114

4. White DB, Lo B. A framework for rationing ventilators and critical care beds during the COVID-19 pandemic. JAMA. 2020;323(18):1773-1774. https://doi. org/10.1001/jama.2020.5046

5. Emanuel EJ, Wetheimer A. Who should get influenza vaccine when not all can? Science. 2006;312(5775):854-855. https://doi.org/10.1126/ science. 1125347

6. White DB, Katz MH, Luce JM, Lo B. Who should receive life support during a public health emergency? Using ethical principles to improve allocation decisions. Ann Intern Med. 2009;150(2):132-138. https://doi.org/10.7326/00034819-150-2-200901200-00011

7. The Commonwealth of Massachusetts Executive Office of Health and Human Services Department of Public Health. Crisis Standards of Care: Planning Guidance for the COVID-19 Pandemic. Accessed August 1, 2020. https:// www.mass.gov/doc/statewide-advisory-committee-recommendations-forstandards-of-care/download?_ga=2.55928739.940920097.159299949195847297.1590861397

8. Brody H, Avery EN. Medicine's duty to treat pandemic illness: solidarity and vulnerability. Hastings Cent Rep. 2009;39(1):40-48. https://doi.org/10.1353/ hcr.0.0104

9. Ruderman C, Tracy CS, Bensimon CM, et al. On pandemics and the duty to care: whose duty? who cares? BMC Med Ethics. 2006;7:E5. https://doi. org/10.1186/1472-6939-7-5

10. Huber SJ, Wynia MK. When pestilence prevails ... physician responsibilities in epidemics. Am J Bioeth. 2004;4(1):W5-11. https://doi. org/10.1162/152651604773067497

11. AMA Council on Ethical and Judicial Affairs. Opinion 9.067 Physician Obligation in Disaster Preparedness and Response. Virtual Mentor. 2010;12(6):459. d10.1001/virtualmentor.2010.12.6.coet1-1006

12. Rothstein MA. Should health care providers get treatment priority in an influenza pandemic? J Law Med Ethics. 2010;38(2):412-419. https://doi. org/10.1111/j.1748-720X.2010.00499.x

13. Rawls J. A Theory of Justice. The Belknap Press: an imprint of Harvard University Press; 1971.

14. Green WS. Parsing reciprocity: questions for the Golden Rule. In: Neusner J, Chilton BD, eds. The Golden Rule: The Ethics of Reciprocity in World Religions. Continuum International Publishing Group; 2008:1-8.

15. Walzer M. Obligations: Essays on Disobedience, War and Citizenship. Harvard University Press; 1970.

16. Persad G, Wertheimer A, Emanuel EJ. Principles for allocation of scarce med ical interventions. Lancet. 2009;373(9661):423-431. https://doi.org/10.1016/ S0140-6736(09)60137-9 